\title{
Reconstruction of the March-August PDSI since 1703 AD based on tree rings of Chinese pine (Pinus tabulaeformis Carr.) in the Lingkong Mountain, southeast Chinese loess Plateau
}

\author{
Q. Cai ${ }^{1}$, Y. Liu ${ }^{1,2}$, Y. Lei ${ }^{1}$, G. Bao ${ }^{3}$, and B. Sun ${ }^{4}$ \\ ${ }^{1}$ The state key laboratory of Loess and Quaternary Geology, Institute of Earth Environment, Chinese Academy of Sciences, \\ Xi'an, 710075, China \\ ${ }^{2}$ Department of Environmental Science and Technology, School of Human Settlements and Civil Engineering, \\ Xi' an Jiaotong University, Xi' an, 710049, China \\ ${ }^{3}$ Key Laboratory of Disaster Monitoring and Mechanism Simulating of Shaanxi Province, Baoji University of Arts and \\ Sciences, Baoji, 721013, Shaanxi, China \\ ${ }^{4}$ Department of Resources, Environment, and Urban Sciences, Xianyang Normal University, Xianyang, 712000, China \\ Correspondence to: Y. Liu (liuyu@loess.llqg.ac.cn) and Q. Cai (caiqf@ieecas.cn)
}

Received: 28 September 2013 - Published in Clim. Past Discuss.: 11 November 2013

Revised: 26 January 2014 - Accepted: 2 February 2014 - Published: 13 March 2014

\begin{abstract}
We utilised tree-ring cores, collected from three sites at Lingkong Mountain located in the southeast part of the Chinese Loess Plateau (CLP), to develope a regional ring-width chronology. Significant positive correlations between the tree-ring index and the monthly Palmer drought severity index (PDSI) were identified, indicating that the radial growth of trees in this region was moisture-limited. The March-August mean PDSI was quantitatively reconstructed from 1703 to 2008 with an explained variance of $46.4 \%$. Seven dry periods during 1719-1726, 1742-1748, 1771-1778, 1807-1818, 1832-1848, 1867-1932 and 19932008 and six wet periods during 1727-1741, 1751-1757, 1779-1787, 1797-1805, 1853-1864 and 1934-1957 were revealed in our reconstruction. Among them, 1867-1932 and 1934-1957 were identified as the longest dry and wet periods, respectively. On the centennial scale, the 19th century was recognised as the driest century. The drying tendency since 1960s was evident. However, recent drought in 1993-2008 was still within the frame of natural climate variability based on the $306 \mathrm{yr}$ PDSI reconstruction. The dry and wet phases of Lingkong Mountain were in accordance with changes in the summer Asian-Pacific oscillation $\left(I_{\mathrm{APO}}\right)$ and sunspot numbers, they also showed strong similarity to other tree-ring based moisture indexes in large areas in and around the CLP, indicating the moisture variability in the
\end{abstract}

CLP was almost synchronous and closely related with largescale land-ocean-atmospheric circulation and solar activity. Spatial correlation analysis suggested that this PDSI reconstruction could represent the moisture variations for most parts of the CLP, and even larger area of northern China and east Mongolia. Multi-taper spectral analysis revealed significant cycles at the inter-annual (2-7 yr), inter-decadal $(37.9 \mathrm{yr})$ and centennial (102 yr) scales. Results of this study are very helpful for us to improve the knowledge of past climate change in the CLP and enable us to prevent and manage future natural disasters.

\section{Introduction}

Various studies have demonstrated that the development of human society was closely related with changes in climate (Xu, 1998; Zhang et al., 2010, 2011; Büntgen et al., 2011). When climate change reaches an extreme level, it causes disaster. Drought is one of the most devastating natural disasters throughout the world, which also strongly influenced monsoon China. In 1999 and 2000, there was a persistent drought in north and northeast China, which caused a $20-30 \%$ loss of agriculture productivity (Wei et al., 2004). At the end of the 1920s, an extraordinary drought affected most parts of 
China, and subsequent drought-induced famines and disease led to the death of 4 million residents in five provinces in north China (Liang et al., 2006; Wang, 2006). An improved knowledge of the characteristics of climate change will enable us to prevent and manage future natural disasters and promote the sustainable development of our society.

It is imperative to identify the features of climate changes in details based on long-term and continuous climatic proxies. Annually dated tree rings are preferable climatic proxies for extending the limited modern meteorological record by analysing the relationship between tree-ring indexes and climatic factors, thereby reconstructing the climate history for centuries to millennia (Zhang et al., 2003; Yang et al., 2009; Zhu et al., 2009; Linderholm et al., 2010; Büntgen et al., 2011; Ohyama et al., 2013). Tree rings have been successfully used to investigate drought history throughout the world (Esper et al., 2007; Cook et al., 2010), including arid to semi-arid areas of China (Liang et al., 2006; Chen et al., 2011a; Fang et al., 2012; Cai and Liu, 2013).

The Chinese Loess Plateau (CLP), one of the cradles of ancient Chinese civilization, covers a large region in the north of China and is one of the most intensive areas of soil and water loss in the world, partly due to limited water resources (Gao et al., 2011). Recent studies have shown that the warmdry trend since the 1950s is clearly evident in the CLP (Yao et al., 2005; $\mathrm{Ma}$ and $\mathrm{Fu}, 2006$ ) and will inevitably lead to the eco-environmental deterioration of this vast region. Investigations of the natural climate background of the CLP are crucial for understanding the processes and characteristics of climate change in this region as well as the current status of the climate, which will contribute to policy guidance from the government. To date, few dendroclimatological studies have been conducted in the central part of the CLP (Du et al., 2007; Cai et al., 2008; Koretsune et al., 2009) because of the scarcity of old trees due to natural geographical conditions and historical reasons. However, previous studies in the marginal area of the CLP (Gao et al., 2005; Fang et al., 2012; Cai and Liu, 2013; Cai et al., 2013) have greatly contributed to our understanding of tree growth-climate relationships and climate change in this region. Even though, additional efforts are required to increase the spatial and temporal coverage, creating opportunities for a wide range of detailed local-toregional climatological studies in this region (Linderholm, et al., 2013).

Chinese pine (Pinus tabulaeformis Carr.), a two-needle conifer species which is endemic to China, is the most widely distributed and the most important afforestation conifer species in northern China. It generally occurs in mountain areas at altitudes of $100-2600 \mathrm{~m}$ (Xu, 1990). It can tolerate very low temperature $\left(-25^{\circ} \mathrm{C}\right)$ and can adapt to live in low soil water availability conditions with well developed root systems. This species has been widely used for dendroclimatic researches in China (Liu et al., 2005; Liang et al., 2007; Cai and Liu, 2013). This paper describes the development of a new long regional tree-ring chronology of the Chinese pine from Lingkong Mountain in the southeast CLP. The main objectives of this work were to (1) determine the response of tree-ring growth to climate; (2) use of the ring-width chronology to develop a 306 yr Palmer drought severity index (PDSI) reconstruction; (3) detect the temporal and spatial representations of this reconstruction as well as the possible driving factors. Results of this work would be conducive to answer the following two questions: Did the drought severity or frequency increase in response to the global warming? Is the drought condition nowadays in Lingkong Mountain unprecedented during the last three centuries?

\section{Materials and methods}

\subsection{Study area and climate}

Lingkong Mountain $\left(112^{\circ} 01^{\prime}-112^{\circ} 15^{\prime} \mathrm{E}, 36^{\circ} 31^{\prime}-36^{\circ} 43^{\prime} \mathrm{N}\right)$ is located in the southeast region of the CLP. The altitude of Lingkong Mountain generally ranges from 1600 to $1850 \mathrm{~m}$ a.s.l., and the highest peak is $1953 \mathrm{ma}$ a.s.l. At the studied sites, Chinese pine, generally $30 \mathrm{~m}$ in height and growing in mountainous brown soil, is the dominant tree species, accompanied by sparse Quercus liaotungensis Koidz., Populus davidiana Dode and Betula platyphylla Suk. This area has a typical temperate continental climate and is subject to the influence of the East Asian summer monsoon (EASM). It is characterised by large precipitation variability, both annually and inter-annually. Thus, droughts and floods frequently occurred in this region. The annual mean temperature of this region is $8^{\circ} \mathrm{C}$, with the highest and lowest temperatures occurring in July $\left(24.10^{\circ} \mathrm{C}\right)$ and January $\left(-4.53^{\circ} \mathrm{C}\right)$, respectively. The annual mean precipitation ranges from 600 to $650 \mathrm{~mm}$, mainly focused in July and $\mathrm{Au}-$ gust, whereas the mean annual evaporation is approximately $1510 \mathrm{~mm}$.

\subsection{Tree-ring data}

In June 2009, Chinese pine tree-ring samples were collected from three different sites in the Lingkong Mountain area (Fig. 1). The first sampling site $\left(112^{\circ} 5.227^{\prime} \mathrm{E}, 36^{\circ} 35.588^{\prime} \mathrm{N}\right.$, 1480-1700 ma.s.l.) was in the national nature reservation park of Lingkong Mountain, labeled LKS, where 60 treering cores from 30 living trees were extracted using the increment borer. The second site $\left(112^{\circ} 5.20^{\prime} \mathrm{E}, 36^{\circ} 46.38^{\prime} \mathrm{N}\right.$, $1450-1650 \mathrm{~m}$ a.s.l.) was located to the northwest of LKS, and labeled WJW, 40 tree-ring cores from 20 living trees were collected from this area. At the third site $\left(112^{\circ} 24.62^{\prime} \mathrm{E}\right.$, $36^{\circ} 53.97^{\prime} \mathrm{N}, 1450 \mathrm{~m}$ a.s.1.), trees older than $100 \mathrm{yr}$ are very difficult to find, so only 8 cores from 4 old healthy trees were collected, this site was named JF. The distance between the three sites was greater than $30 \mathrm{~km}$.

Tree-ring samples were processed according to the standard dendrochronological technique (Cook and Kairiukstis, 1990). The Skeleton-plot cross-dating method (Stokes and 


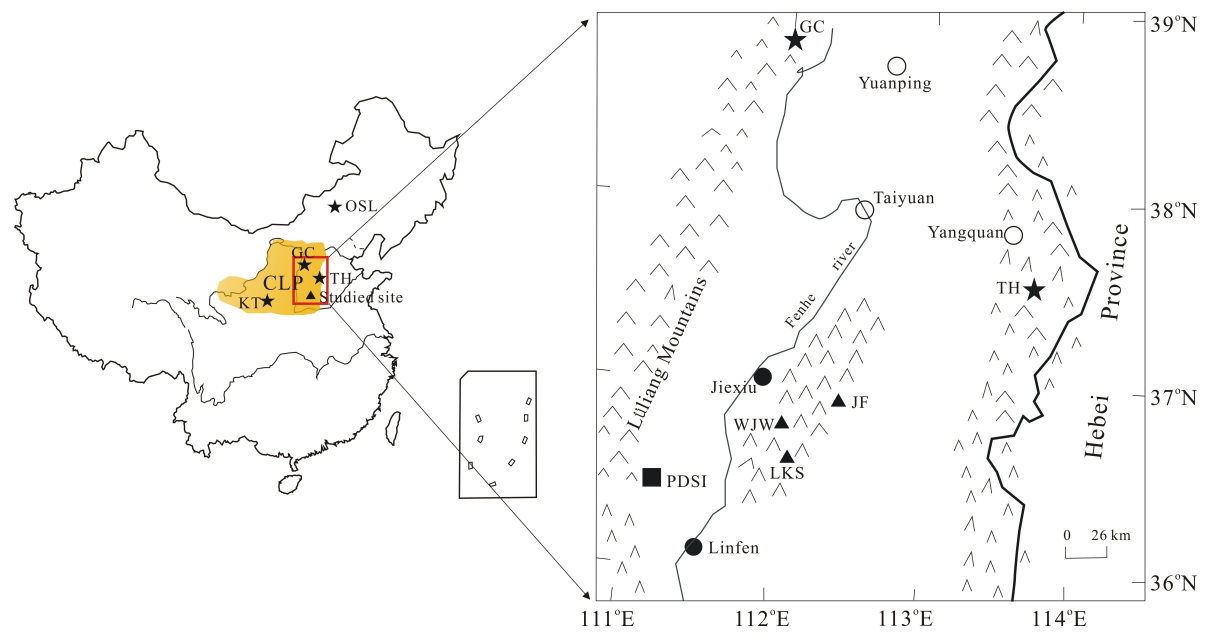

Fig. 1. Location of the sampling sites $(\boldsymbol{\Delta})$, meteorological stations $(\bullet)$, Dai-PDSI $(\boldsymbol{\square})$ and other tree-ring based PDSI reconstruction series mentioned in the text $(\star)$. KT: Kongtong Mountain; TH: Taihang Mountain; GC: Guancen Mountain; OSL: Ortindag Sand Land. The area highlighted in yellow indicates the general location of the Chinese Loess Plateau (CLP).

Smiley, 1968) was adopted to preliminarily assign the calendar years to each growth ring. All the tree rings in each core were measured to the nearest $0.01 \mathrm{~mm}$. The COFECHA programme (Holmes, 1983) was utilised to estimate the quality of cross-dating and ring-width measurements. Series with short ages or that were abnormal in comparison with the majority of series were discarded from the chronology construction. Because the COFECH results showed that strong similarities existed among the ring-width series from different sites, we finally combined all of the samples into one group to produce a regional chronology. The tree-ring width chronology was developed using the ARSTAN program (Cook, 1985). To retain as much long-term climate variance as possible, negative exponential curve or straight line with negative slope was applied to each tree-ring measurement series to remove the non-climate trends related to tree age or the effects of stand dynamics. We divided the raw data of each ring width by the corresponding year's value of the fitted curve to give a dimensionless index. Finally, all individual indices were combined to produce a standard STD chronology by means of "biweight robust mean". A subsample signal strength (SSS) threshold of 0.85 (Wigley et al., 1984) was applied to assess the reliable starting year of the chronology, excluding the low quality of earlier years due to low sample size. The signal strength of the chronology was also evaluated over time using statistics of the calculated running series of average between-tree correlations (RBAR) (Briffa and Jones, 1990) and the running express population signal (EPS) (Wigley et al., 1984) based on a 50 yr window.

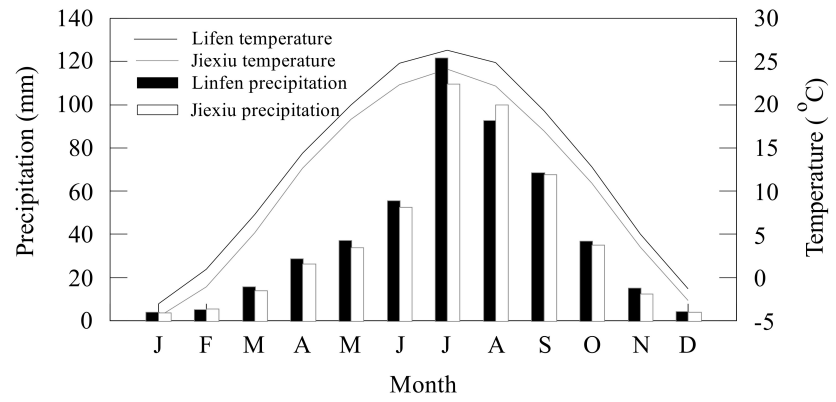

Fig. 2. Monthly precipitation and monthly mean temperature distribution of the two meteorological stations from 1954 to 2008 AD.

\subsection{Meteorological data}

Two meteorological stations are located near the sampled sites (Fig. 1). The nearest station is Jiexiu $\left(111^{\circ} 55^{\prime} \mathrm{E}\right.$, $37^{\circ} 02^{\prime} \mathrm{N}, 743.9 \mathrm{~m}$ a.s.l.) and the other is Linfen $\left(111^{\circ} 30^{\prime} \mathrm{E}\right.$, $36^{\circ} 04^{\prime} \mathrm{N}, 450.3 \mathrm{~m}$ a.s.l.). Both stations have $55 \mathrm{yr}$ instrumental records spanning from 1954 to $2008 \mathrm{AD}$. As shown in Fig. 2, monthly precipitation and mean temperature records at the two stations showed similar variation, indicating a regional coherence of climate. Therefore, the monthly precipitation amount and monthly mean temperature records from the two stations were extracted. Palmer drought severity index (PDSI) is a metric that can be used to effectively evaluate moisture condition in an area (Dai et al., 2004) and has been applied in dendroclimatological studies to determine moisture conditions worldwide (Cook et al., 2010; Tei et al., 2013). In the present paper, Dai-PDSI data from 1954 to $2005 \mathrm{AD}$ from the nearest point $\left(111.25^{\circ} \mathrm{E}, 36.25^{\circ} \mathrm{N}\right)$ were also chosen to compare with the tree-ring index. 

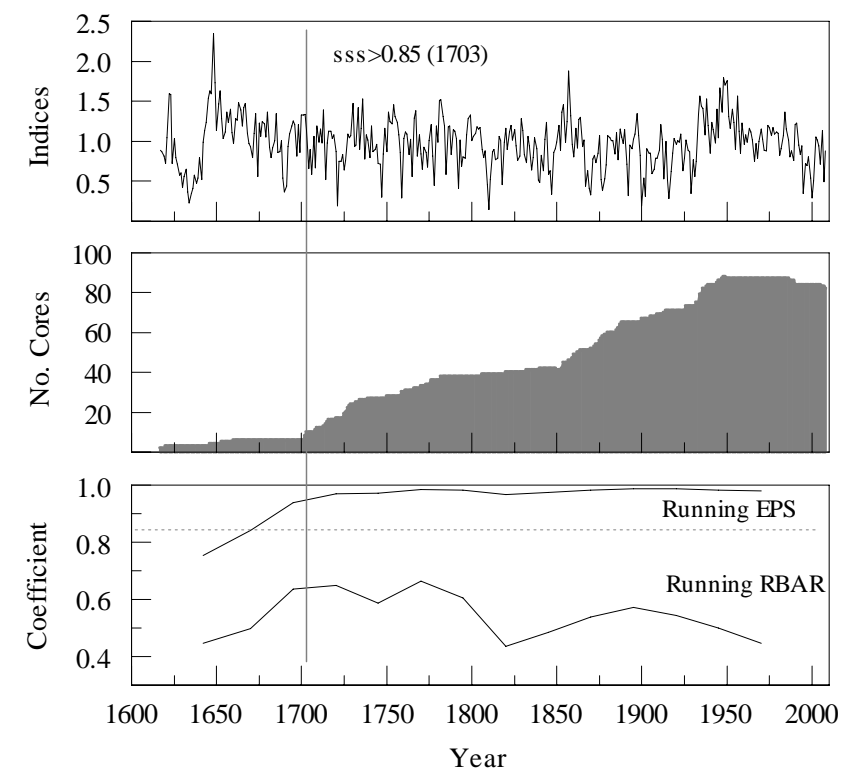

Fig. 3. (a) The regional tree-ring chronology of Lingkong Mountain, (b) number of cores and (c) EPS and RBAR statistics.

\subsection{Statistical analysis}

Climate-growth relationships were investigated using Pearson correlation analysis between the tree-ring chronology and the meteorological records as well as the Dai-PDSI data. A simple linear regression model was adopted to reconstruct the mean PDSI value from March to August. The fidelity of the reconstruction was verified by comparison with the DaiPDSI data and checked by the split calibration-verification method (Meko and Graybill, 1995). Furthermore, the stability of the regression model was also tested by applying the Bootstrap (Cook and Kairiukstis, 1990) and Jackknife (Efron, 1979) statistical methods, which have been adopted in dendroclimatology (Liu et al., 2013). The temporal and spatial representativeness of the PDSI reconstruction was tested by comparisons with other tree-ring-based moisture indexes from nearby area and spatial correlation analysis between the Dai- and reconstructed March-August PDSI and the PDSI grid dataset according to KNMI Climate Explore (http://climexp.knmi.nl). Multi-taper spectral analysis (MTM) (Mann and Lees, 1996) was conducted to identify the periodicities in the reconstructed series.

\section{Results}

\subsection{Tree-ring chronology}

All of the final 88 ring-width measurements (the mean segment length is $180.5 \mathrm{yr}$ ) from the three different sites were highly correlated $(r=0.71)$, and were successfully combined to develop a regional tree-ring chronology spanning from

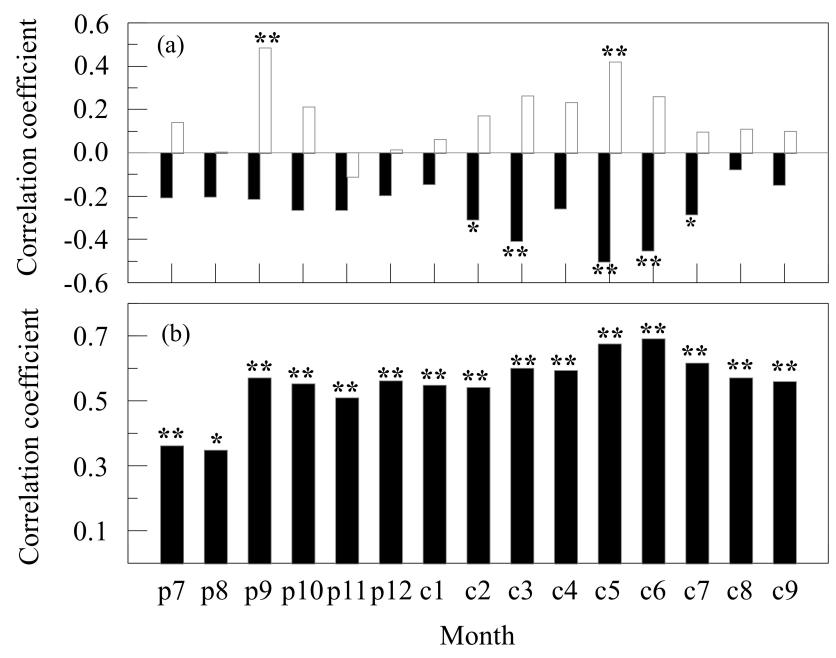

Fig. 4. Correlations of the ring-width indices with (a) the monthly mean temperature (black bars) and monthly precipitation (white bars) records obtained from the Jiexiu station during 1954-2008 AD and (b) PDSI data during the interval of 1954-2005 AD. * indicates correlations exceeding the 0.05 confidence level; ${ }^{* *}$ indicates correlations exceeding the 0.01 confidence level; $p$ : previous year; $c$ : current year.

1617 to $2008 \mathrm{AD}$ (Fig. 3). The most credible starting year of the chronology was $1703 \mathrm{AD}$, corresponding to 10 cores based on the SSS $>0.85$ criterion. During the reliable period of the chronology, the mean EPS value was greater than 0.94, far higher than the acceptable threshold of 0.85 (Wigley et al., 1984), and RBAR also showed high and stable value (Fig. 3). The signal to noise ratio (SNR) was 36.36, and variance in the first eigenvector (PC1) was 42.52, demonstrating strong signal strength among all trees involved in the chronology.

\subsection{Ring growth-climate relationship}

Because the tree-ring chronology had similar response to the climatic factors of the two meteorological stations, we only showed the results between the tree-ring index and climatic factors from the Jiexiu station. As shown in Fig. 4a, the regional tree-ring chronology showed positive correlation with the monthly precipitation amount of previous September (0.48) and current May (0.42) at the 0.01 confidence level. Additionally, significant negative relationships were found with the monthly mean temperature of March $(-0.41)$, May $(-0.5)$ and June $(-0.45)$ at the 0.01 confidence level and with the monthly mean temperature of February $(-0.31)$ and July $(-0.28)$ at the 0.05 confidence level.

Similar to studies in other areas of northern China (Fang et al., 2009; Cai et al., 2013), correlations of tree rings with monthly Dai-PDSI were much higher than with precipitation or temperature (Fig. 4b). The most significant $(p<0.01)$ correlations was found in May (0.68) and June (0.69) followed 
Table 1. Statistics of the regression model.

\begin{tabular}{lllll}
\hline \multicolumn{2}{c}{ Calibration (1954-2005 AD) } & & \multicolumn{2}{c}{ Verification (1954-2005 AD) } \\
\cline { 1 - 3 } \cline { 5 - 6 } & & & $\begin{array}{l}\text { Jackknife } \\
\text { Mean (range) }\end{array}$ & $\begin{array}{l}\text { Bootstrap (80 iterations) } \\
\text { Mean (range) }\end{array}$ \\
\hline$r^{\mathrm{a}}$ & 0.681 & & $0.68(0.63-0.71)$ & $0.68(0.47-0.85)$ \\
$R^{2 \mathrm{~b}}$ & 0.464 & & $0.46(0.40-0.51)$ & $0.47(0.22-0.73)$ \\
$R_{\mathrm{adj}}^{2 \mathrm{c}}$ & 0.453 & & $0.45(0.38-0.50)$ & $0.46(0.20-0.72)$ \\
Standard error of estimate & 1.939 & & $1.94(1.82-1.96)$ & $1.89(1.53-2.27)$ \\
$F^{\mathrm{d}}$ & 43.26 & & $42.47(32.18-51.06)$ & $48.30(13.94-132.75)$ \\
$P^{\mathrm{e}}$ & 0.0001 & & $0.0001(0.00-0.00)$ & $0.0001(0.00-0.00)$ \\
\hline
\end{tabular}

${ }^{\mathrm{a}} r$ : correlation coefficient of the regression model; ${ }^{\mathrm{b}} R^{2}:$ explained variance of the regression model; ${ }^{\mathrm{c}} R_{\text {adj }}^{2}:$ explained variance of the regression model after adjustment for loss of degrees of freedom; ${ }^{\mathrm{d}} F: F$ test result; ${ }^{\mathrm{e}} P$ : significance level.
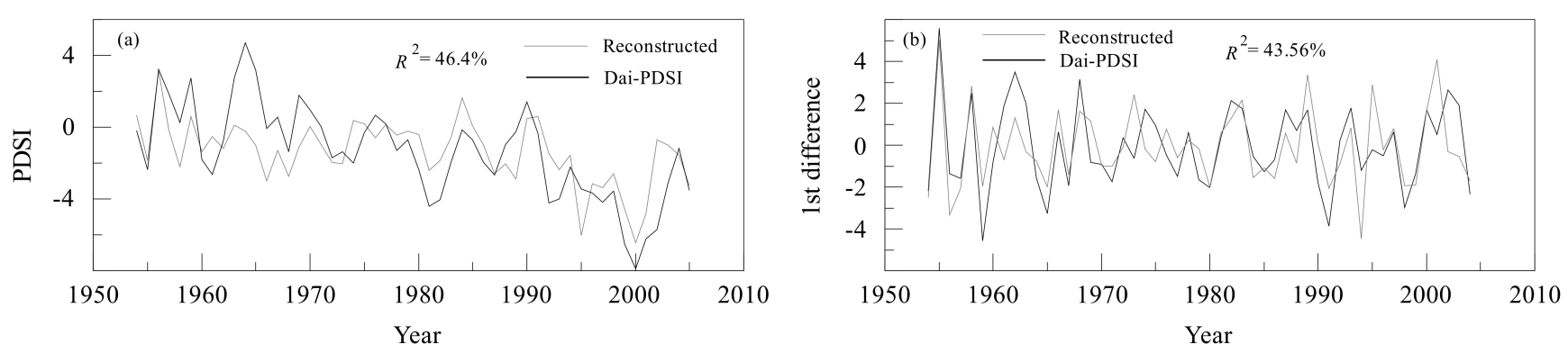

Fig. 5. Comparisons (a) between reconstructed PDSI and Dai-PDSI, and (b) between the first differences of reconstructed and Dai-PDSI over their common period of 1954-2005 AD.

by July (0.62) and March (0.6). Although the highest correlation was observed between tree rings and the monthly combination of Dai-PDSI from May to June $(r=0.697, p<0.001)$, March-August PDSI $(r=0.681, p<0.001)$ was chosen for the reconstruction considering that both the moisture conditions in spring (March to May) and summer (June to August) are pivotal for agricultural production (Ma et al., 2006; Xiao et al., 2007) and tree growth in northern China (Du et al., 2007; Cai et al., 2008; Koretsune et al., 2009; Cai and Liu, 2013).

\subsection{PDSI reconstruction}

Using the tree-ring chronology from Lingkong Mountain $(\mathrm{RC})$ as predictor, a simple linear regression model $\left(\mathrm{PDSI}_{38}=7.517 \times \mathrm{RC}-8.631\right)$ was designed to reconstruct March-August PDSI (PDSI 38 ) variation. Figure 5a demonstrates that the reconstructed PDSI simulates the Dai-PDSI record very well, though the high PDSI values during the 1960s were not well predicted. The reconstruction could explain $46.4 \%$ of the Dai-PDSI record (45.3\% after adjustment for the loss of degrees of freedom) over the calibration period from 1954 to 2005 AD. In case of high correlation caused by trends, the correlation coefficient $(r)$ between the two first difference series of reconstructed PDSI and Dai-PDSI was also calculated (Fig. 5b). The $r$ value was 0.66 , indicating a high coherence between high frequency variation of the reconstructed and Dai-PDSI series.

Result of the split period calibration-verification test showed that the regression model is stable over time. The explained variance $\left(R^{2}\right)$ for the verification period 1983-2005 was $52.1 \%$, and reduction of error (RE) and coefficient of efficiency (CE) were 0.603 and 0.375 , respectively, when the data during 1954-1982 was used to establish the regression model. $R^{2}$, RE and CE were $32.3 \%, 0.411$ and 0.113 , respectively for the verification period 1954-1973, when data during 1974-2005 was chosen as calibration. RE and CE, the two rigorous verification statistics during verification periods showed positive values, indicating sufficient similarity exists between the reconstruction and Dai-PDSI data (Cook et al., 1999). The statistical results of Bootstrap and Jackknife analysis are shown in Table 1 . The values of $r, R^{2}\left(R_{\mathrm{adj}}^{2}\right)$, standard error of estimate, $F$ and $P$ closely resemble the statistics determined for the total dataset. The above tests indicate that the regression model is stable and suitable for further PDSI reconstruction.

We subsequently extended the March-August mean PDSI variation back to $1703 \mathrm{AD}$ (Fig. 6a), the longest series in the eastern part of the CLP to date. The reconstruction exhibited considerable fluctuations on both the annual and decadal scales. 


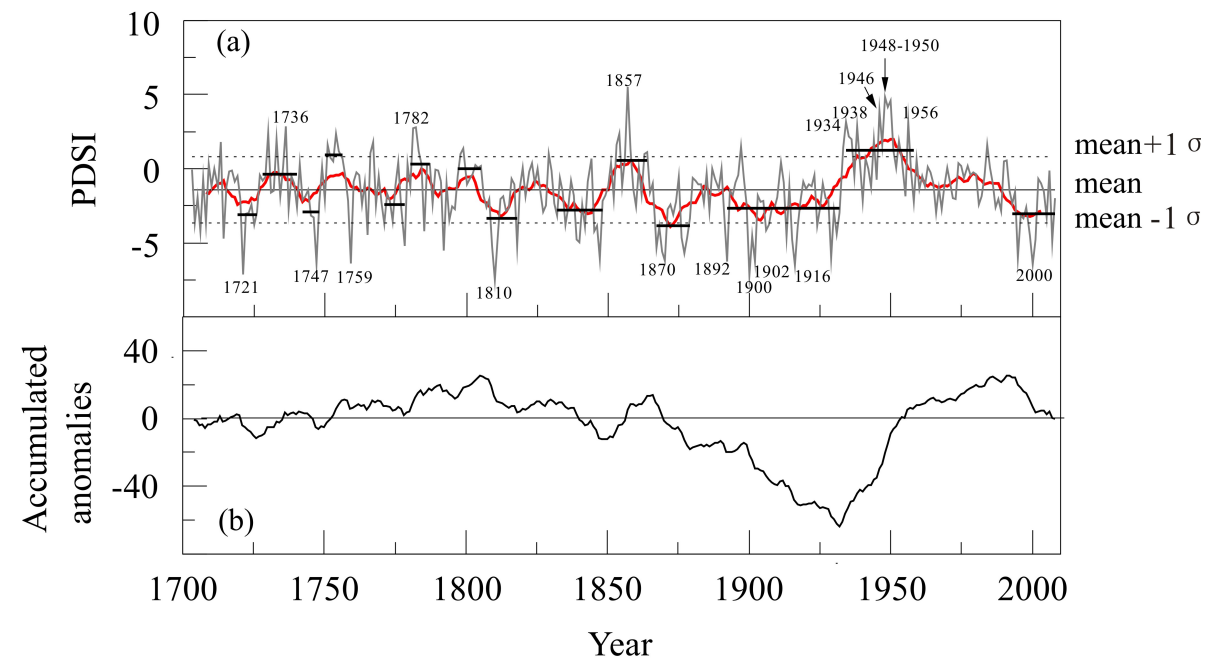

Fig. 6. (a) March-August PDSI reconstruction from 1703 to 2008 AD. The thick red line is the 11 yr moving average, the long horizontal line is the mean PDSI value of 1703-2008 AD, and the short horizontal lines are the mean PDSI values for different dry/wet periods; (b) accumulated anomalies (AC) of the PDSI reconstruction.

\section{Discussions}

\subsection{Climate-growth relationship}

Lingkong Mountain belongs to the semi-arid area where annual evaporation is more than twice of annual precipitation. High precipitation during the growth season actually benefits the radial growth of tree by providing necessary water for the radial cell division and elongation, while low precipitation limited the radial growth. Inversely, increased temperature before and during the growth season inevitably strengthen the water stress by accelerating water consumption in the soil and trees through evaporation and transpiration, resulting in the formation of narrow rings, and vice versa. Reasonably, positive correlation of tree rings with monthly precipitation and negative correlations with monthly mean temperature in current growth year was identified in this study, and this climate-growth pattern was generally reported in the arid to semi-arid CLP (Gao et al., 2005; Liu et al., 2005; Cai and Liu, 2013) and other areas of northern China (Liang et al., 2007).

In the present work, monthly mean temperature from March to August exerts more important influences upon tree growth than monthly precipitation (Fig. 4), which is similar to studies in the Kongtong Mountain (Fang et al., 2012), Guiqing Mountain (Fang et al., 2010a) and the Ortindag Sand Land (Liang et al., 2007), showing the temperatureinduced water stress was likely the key factor limiting tree growth. The correlation analysis between Dai-PDSI and treering chronology further tested the above hypothesis. Significant correlation is identified from March to August, especially significant in May and June when the temperature is comparatively high and precipitation is very low (Fig. 2), indicating an intensified drought stress. PDSI is a measurement of dryness which was calculated based on a water balance equation, depending on not only temperature and precipitation, but also other parameters such as evapotranspiration and recharge rates. Thus, it is unsurprised that the monthly PDSI of previous year had significant influence on tree growth due to the well-known lag effect, though climatic factors in previous year (except the precipitation of September) showed weak correlation with tree growth.

Interestingly, the period of limiting months coincided with the results of cambial activity of trees in northern China. Tree-ring anatomical analysis disclosed that the radial wood formation of Chinese pine usually started at the end of April (Zhang et al., 1982), and fast growth usually happened from May to August (Zhang et al., 1982; Liang et al., 2009). Similar finding was reported from Larixprincipis-rupprechtii, a different coniferous species from Liupan Mountain, northcentral China (Guan et al., 2007). Location of our studied sites is far south than the above reported sites, and it is warmer and wetter, therefore, it is possible that the radial growth of tree in Lingkong Mountain may start earlier.

\subsection{Annual, inter-annual and centennial variation of the PDSI}

The mean PDSI value of the reconstruction over the entire study period (1703-2008 AD) was -1.45 , and the standard deviation $(\sigma)$ was 2.23 . By defining extremely wet years as those having values greater than $0.78($ mean $+1 \sigma)$ and extremely dry years as values lower than $-3.68($ mean $-1 \sigma)$, the 10 driest yeas were identified as $1810(-7.50), 1900$ $(-7.20), 1721(-7.16), 1916(-6.52), 2000(-6.45), 1759$ $(-6.41), 1747(-6.38), 1902(-6.29), 1892(-6.25)$ and $1870(-6.18)$, and the top 10 wettest years were 1857 (5.51), 1948 (4.86), 1950 (4.58), 1949 (4.18), 1946 (3.92), 
1956 (3.16), 1934 (3.15), 1938 (2.86), 1736 (2.85) and 1782 (2.78), respectively. However, we should point out that lowfrequency variation of the reconstructed PDSI was more reliable than high-frequency variation.

A persistent drought event usually has more significant impact on agricultural products and social stability than that of a single year (Xiao et al., 2011). Overall, seven comparatively dry and six comparatively wet periods were observed based on the $11 \mathrm{yr}$ moving average of the reconstruction (Table 2). It is visible that the severity and duration of dry or wet events seemingly strengthened after 1800 AD compared with the earlier stages, possibly due to the impact of global warming. Even so, the recent drought in 1993-2008 was still within the historical framework.

During the past $306 \mathrm{yr}, 1867-1932$ AD was the longest dry period in the reconstruction (with $10 \mathrm{yr}$ disturbance of normal years from 1880-1890 AD); the mean PDSI value of this duration was -2.62 , and the mean value of its early part (1867-1879 AD) was -3.88 , indicating that this was the driest period in the reconstruction (Fig. 6a). Historical documents recorded three distinguished consecutive drought events in northern China caused by climate change since the Qing Dynasty during 1719-1723, 1876-1878 and 19271930, respectively (Z. Z. Zeng et al., 2009; Hao et al., 2010). Among them, the 1876-1878 and 1927-1930 drought events ranked as two of the most severe natural disasters in Chinese history and have drawn significant attention from scientists due to their devastating consequences on society (Hao et al., 2010; Zhou et al., 2010). These two recent extremely dry events, the 1920s drought in particular, have been captured by many other tree-ring reconstructions in the CLP and other regions of China (Liu et al., 2003a, b, 2005, 2010; Liang et al., 2007; Chen et al., 2011a, 2012; Deng et al., 2013; Kang et al., 2013) as well as Mongolia (Pederson et al., 2001). The 1920s drought was also revealed by a weakened signal of the EASM indicated by a dry-wet mode index (Qian et al., 2012). In the present paper, these two drought events were also revealed by very low PDSI values during 1876-1878 (-5.02) and 1928-1931 (-3.86) (Fig. 6a). However, the drought in 1719-1723 is seldom mentioned in previous dendroclimatological reports due to the limited length of reconstruction (Fang et al., 2010a, 2013). 1721 was documented as an extremely dry year in the whole region of Shaanxi province, a neighbourhood of Lingkong Mountain (Yuan, 1994). In this year, the farmers reaped nothing at harvest time due to low precipitation in spring and summer, and many people died of starvation due to this drought-induced famine. By analysing historical documents of eastern China, Zhang (2004) identified 1721-1723 as one of the tenth typical dry period during the last $1000 \mathrm{yr}$. This drought event affected at least four provinces in eastern China, including our studied area. In this study of Lingkong Mountain, 1721 was identified as the third driest years, and 1719-1726 was identified as one of the dry periods during the past $306 \mathrm{yr}$ (Table 2). The mean PDSI value from 1721 to 1723 was -4.39 ,
Table 2. Persistent dry and wet periods during 1703-2008 AD.

\begin{tabular}{|c|c|c|c|}
\hline \multicolumn{2}{|c|}{ Dry periods } & \multicolumn{2}{|c|}{ Wet periods } \\
\hline Time span & $\begin{array}{l}\text { Mean } \\
\text { PDSI } \\
\text { value }\end{array}$ & Time span & $\begin{array}{l}\text { Mean } \\
\text { PDSI } \\
\text { value }\end{array}$ \\
\hline 1719-1726 & -3.11 & $1727-1741$ & -0.39 \\
\hline $1742-1748$ & -2.94 & $1751-1757$ & 0.93 \\
\hline $1771-1778$ & -2.44 & $1779-1787$ & 0.28 \\
\hline 1807-1818 & -3.21 & 1797-1805 & 0.03 \\
\hline $1832-1848$ & -2.78 & $1853-1864$ & 0.57 \\
\hline 1867-1932 & -2.62 & 1934-1957 & 1.36 \\
\hline 1993-2008 & -3.03 & & \\
\hline
\end{tabular}

which is much lower than the mean PDSI value of this reconstruction. This drought was also recorded by a joint investigation based on drought/flood index and tree-ring records in 1720-1722 at Luya Mountain (Yi et al., 2012), which is approximately $700 \mathrm{~km}$ north of studied area. The above analysis demonstrated the ability of this PDSI reconstruction to reproduce the drought history in the Lingkong Mountain area, even northern China.

Moreover, 1934-1957 AD was the longest and wettest period in the reconstruction, with a mean PDSI value of 1.36, corresponding to a strong EASM stage (Liu et al., 2003b). This wet phenomenon was also captured by tree-ring records from different areas of Inner Mongolia and Korea (Liang et al., 2007; Chen et al., 2012) as well as by studies from other regions of northern China (Fig. 7).

The PDSI reconstruction indicates a decreasing trend since 1958 AD, especially after the mid of 1960s, implying a gradually deteriorating moisture condition in the studied area against the background of global warming. The evident dry time appeared during 1993-2008 AD, however, it is still within the frame of natural climate variability. The drying trend at Lingkong Mountain in recent decades is also accorded with the weakening of East Asian monsoon since the mid of 1960s (Guo et al., 2004; G. Zeng et al., 2009).

The accumulative anomalies of the PDSI (AC), achieved by calculating the cumulative departure from the arithmetic mean for the period of reconstruction (Wei, 2007), can intuitively and effectively evaluate the long-term trend of dryness and wetness (Tian et al., 2007). The long-term trends of decreasing and increasing movement of AC indicate the persistently dry or wet conditions. As shown in Fig. 6b, the reconstructed March-August PDSI showed clearly centennial variations. The studied area was comparatively wet during the 18th century, with a slight increasing trend of AC from 1703 to 1806 . From 1807 to 1932, AC generally indicated a long and sharp decreasing trend, demonstrating a persistent dry time. From 1932 to the end of the 1950s, a sharply increased AC was observed, followed by a comparatively stable stage of AC during the 1960s-1980s, showing 


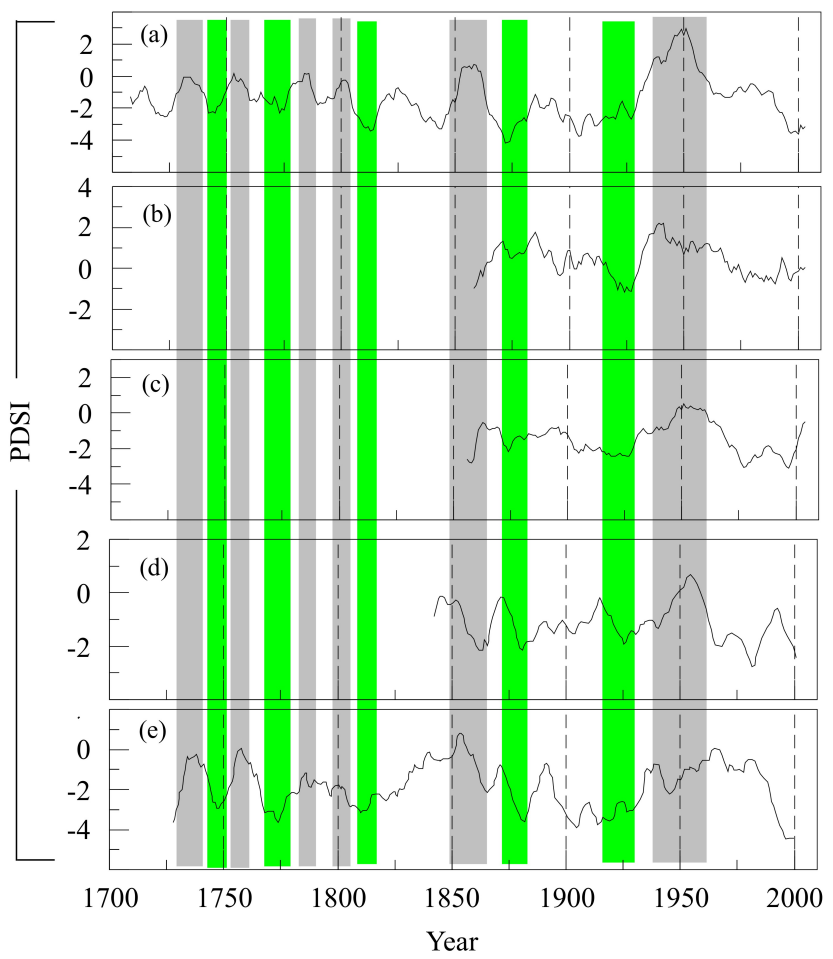

Fig. 7. Comparisons of the March-August mean PDSI reconstruction (a) with the April-July PDSI reconstruction of the Guancen Mountain (Sun et al., 2012) (b), the May-June mean PDSI of the Taihang Mountain (Cai and Liu, 2013) (c), the May-July PDSI reconstruction in the Ortindag Sand Land, east Inner Mongolia (Liang et al., 2007) (d), and (e) the May-July mean PDSI reconstruction for the Kongtong Mountain, Gansu Province (Song and Liu, 2011). The lines are the $11 \mathrm{yr}$ moving average. Green and grey bars show the dry and wet periods, respectively. Locations of these compared PDSI series were shown in Fig. 1.

a comparatively wet condition; however, after the 1990s, AC decreased sharply, which meant a clearly dry time appeared. Therefore, we could say that the 19th century was the driest century of the past three centuries at Lingkong Mountain. Similar conclusions have also been drawn concerning Mongolia (Pederson et al., 2001) and northeastern China (Chen et al., 2011, 2012), as well as the eastern central High Asia (Fang et al., 2010b) based on tree-ring materials.

\subsection{Temporal and spatial representation of the PDSI reconstruction}

The dry (wet) durations in our reconstruction not only agree well with the nearby PDSI reconstructions (Figs. 1 and 7) for the Guancen Mountain (Fig. 7b, Sun et al., 2012) and the Taihang Mountain (Fig. 7c, Cai and Liu, 2013), about 260 and $200 \mathrm{~km}$ away from the studied sites, respectively, but are also comparable to those from the Ortindag Sand Land, east Inner Mongolia (Fig. 7d, Liang et al., 2007) and Kongtong Mountains (Fig. 7e, Song and Liu, 2011), which are 840 and
$560 \mathrm{~km}$ away from the studied sites, respectively. The dry period at $1870 \mathrm{~s}-1880 \mathrm{~s}$ and the end of the 1920s and the wet period around the 1950s are observed in almost all of the series. Compared with the comparatively longer PDSI reconstruction in the Kongtong Mountains (Fig. 7e), the wet durations during 1727-1741, 1751-1757, 1779-1805 and 18531864 AD were approximately synchronous at these two sites, and the dry periods during 1742-1748, 1771-1778, 18071818 and the longest dry period during 1867-1932 AD were comparable, although differences existed in the intensity and length of their durations. Moreover, our PDSI reconstruction was also comparable to a nearby tree-ring-based March-July runoff reconstruction for the upper Fenhe River basin (Sun et al., 2013) and tree-ring based precipitation reconstruction of Helan Mountain in north-central China (Liu et al., 2005).

The March-August Dai-PDSI exhibited significant and positive correlation with the March-August PDSI grid dataset over a sizable region around the studied site in the CLP, and also showed significant positive correlations with that of middle-east Inner Mongolia and east Mongolia during 1954-2005 AD (Fig. 8a). A similar correlation pattern was observed between the reconstructed March-August PDSI and the PDSI grid dataset (Fig. 8b), which tentatively indicated that our PDSI reconstruction successfully simulated the Dai-PDSI values and can be used to indicate the moisture conditions for a broad region surrounding the Lingkong Mountain in the CLP over the past $306 \mathrm{yr}$.

\subsection{Possible linkage with summer Asian-Pacific oscillation and solar activity}

The climate in northern China is known to be strongly affected by the EASM system, which was induced by largescale thermal difference between the land and sea. The abnormal behaviours of the EASM often result in floods or droughts in the monsoon region. Zhou et al. (2009) reconstructed a June-August Asian-Pacific Oscillation index $\left(I_{\mathrm{APO}}\right)$ to investigate the long-term variation of the EASM. The Asian-Pacific oscillation (APO) is defined as a zonal seesaw of the tropospheric temperature in the mid-latitudes of the Asian-Pacific region (Zhao et al., 2008). When the troposphere is cooling (warming) in the mid-latitudes of the Asian continent, it is warming (cooling) in the mid-latitudes of the central and eastern North Pacific. The calculated correlation coefficient $(r)$ between our reconstructed PDSI and the $I_{\mathrm{APO}}$ was $0.29(1703-1985, p<0.001)$, and $r$ was 0.44 $(p<0.001)$ after the two series were smoothed using an $11 \mathrm{yr}$ moving average (Fig. 9a), showing the long-term variation characteristics of the two series are similar. All of the series in Fig. 7 correspond to special regions influenced by the EASM, and thus, the isochronous variation of the moisture indicators at different sites is intuitively shown. Moreover, 2-7 yr cycles were not only detected by the MTM analysis of the PDSI reconstruction (Fig. 10), but also existed in the $I_{\mathrm{APO}}$ series (Chen et al., 2011b). The above analysis suggested that 

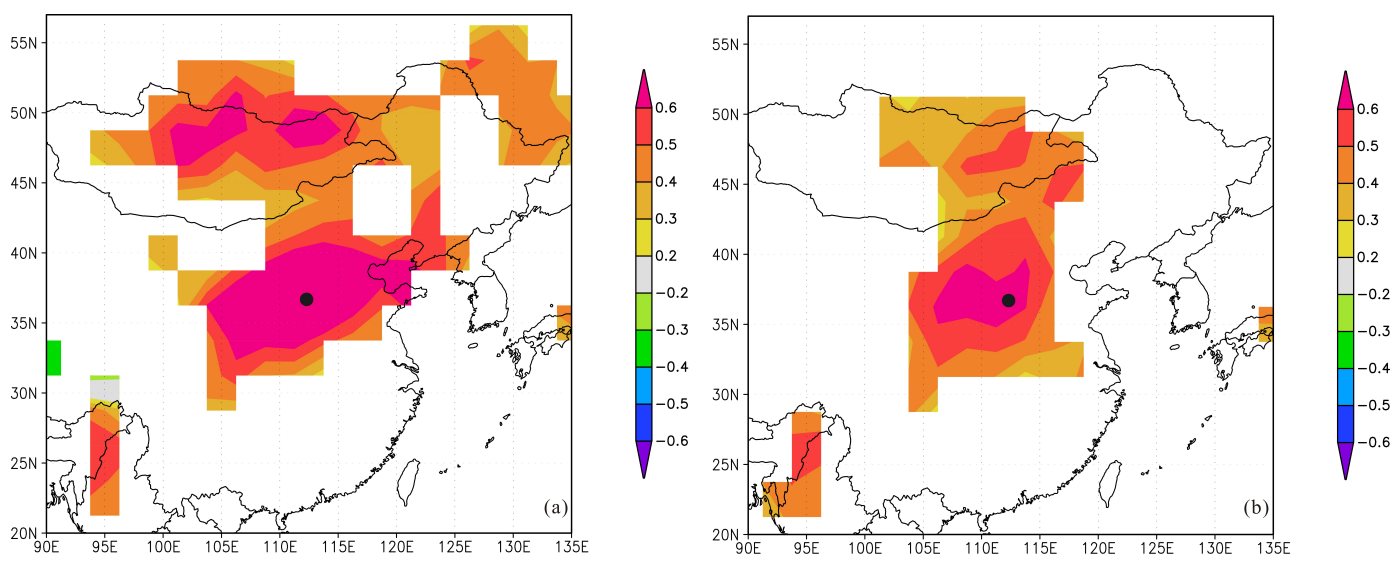

Fig. 8. Spatial correlations between the Dai (a) and reconstructed (b) PDSI of March-August and the concurrent grid dataset of the PDSI over their overlapping periods (1954-2005) (http://climexp.knmi.nl). The black dot indicates our sampling site.
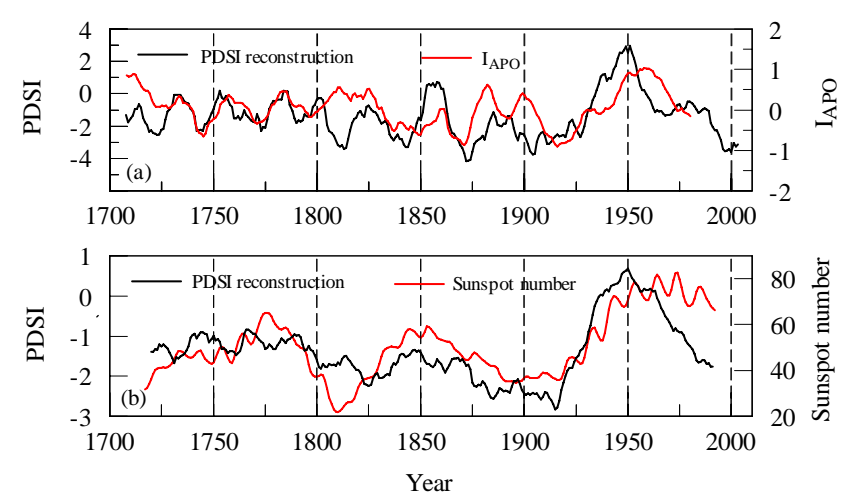

Fig. 9. Comparisons (a) between the $11 \mathrm{yr}$ moving average of the PDSI reconstruction and the summer $I_{\mathrm{APO}}$ (Zhou et al., 2009) and (b) between the $35 \mathrm{yr}$ moving average of the PDSI reconstruction and the sunspot number time series.

our reconstructed PDSI variation was influenced by the largescale land-ocean-atmospheric circulation systems.

Theoretically, on the decadal scale rather than the annual scale, when $I_{\mathrm{APO}}$ was in stronger stages, the thermal contrast between eastern Asia and the North Pacific was strengthened because the low-pressure system of lower-troposphere over eastern Asia strengthens, and the western Pacific subtropical high strengthens with its location shifting northwards (Zhao et al., 2007, 2008). Therefore, lower-troposphere of the East Asian region was dominated by stronger southwesterly winds, in other words, stronger EASM, resulting in more rainfall and wet condition in North China, and vice versa.

The $37.9 \mathrm{yr}$ cycle detected by the MTM analysis (Fig. 10) was very similar to the $38 \mathrm{yr}$ cycle in the $2485 \mathrm{yr}$ temperature reconstructions in the northeastern Tibetan Plateau (Liu et al., 2011), to the 35-38 yr cycle in a tree-ring-based streamflow reconstruction for the upper Yellow River (Gou et al., 2010) and to the $34.1 \mathrm{yr}$ cycle in a tree-ring network-based spatial drought reconstruction for central high Asia (Fang

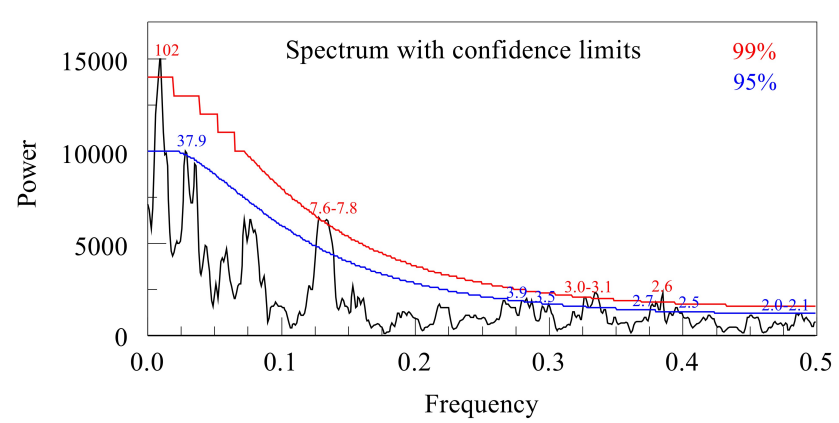

Fig. 10. The multi-taper spectrum analysis of the reconstructed PDSI. The blue line and red line show the 95 and $99 \%$ confidence limits, respectively.

et al., 2010b). Considering the limited length of our reconstruction $(306 \mathrm{yr})$, the $102 \mathrm{yr}$ cycle $(p<0.01)$ may not be reliable. However, century-scale variations were important cycles of solar activity, which complexly influence the Earth's climate (Liu et al., 2011). A similar centennial spectrum peak was identified in the Heng Mountain area of northern China (Cai et al., 2013) and the northeastern Tibetan Plateau (Liu et al., 2011). Both the 37.9 and $102 \mathrm{yr}$ cycles resemble the 35 yr Bruckner (Raspopov et al., 2004) and Gleissberg cycles of solar activity (Sonett et al., 1990; Braun et al., 2005), respectively.

Sunspots are temporary phenomena on the photosphere of the sun that appear visibly as dark spots compared to surrounding regions. It is one of the most basic and obvious phenomenon of solar activity. To further study the influence of solar activity on the dry/wet conditions in Lingkong Mountain, the sunspot time series from 1700 to 2009 were derived from National Geophysical Data Center (http://www.ngdc. noaa.gov/) to compare with our PDSI reconstruction. The low-frequency variations of the two series, after 11 and $35 \mathrm{yr}$ smoothing, significantly correlated with each other, $r=0.35$ 
$p<0.01)$ and $0.68(p<0.01)$, respectively. As shown in Fig. 9b, dry conditions in the studied sites appeared when the sunspot numbers were low, and the contrary when the sunspot numbers were high. This convincingly supported the influence of solar activity on moisture variations in the Lingkong Mountain area.

\section{Conclusions}

Using a moisture-limited regional tree-ring chronology developed from Lingkong Mountain in the southeast CLP, we reconstructed the March-August mean PDSI variations from 1703 to 2008 with an explained variance of $46.4 \%$. The reconstructed PDSI simulated the Dai-PDSI reasonably well and exhibited considerable fluctuations on both the annual and decadal scales. It revealed seven comparatively dry and six comparatively wet periods over the past 306 yr. 18671932 and 1934-1957 AD were the longest dry and wet period, respectively. It is visible that the severity and duration of dry or wet events seemingly strengthened after $1800 \mathrm{AD}$, possibly due to the impact of global warming. However, the recent drought in 1993-2008 was still within the historical framework. The three extreme drought events during 1719-1723, 1876-1878 and 1927-1930 in northern China since the Qing Dynasty were successfully captured in our reconstruction, demonstrating its ability to reproduce the drought history in the Lingkong Mountain area. The warm and dry phases of Lingkong Mountain were in accordance with changes of sunspot numbers and $I_{\mathrm{APO}}$ (an indicator of EASM strength), suggesting the influence of solar activity, land-ocean-atmospheric circulation systems on the moisture conditions in the studied area. The PDSI reconstruction was temporally and regionally representative by comparing with other tree-ring based moisture reconstructions around the studied site in northern China and spatial correlation analysis, although differences existed in the intensity and length of the dry/wet durations in different areas. This manuscript not only contributes a new dataset for this area, stepping forward to a much denser and wider drought-sensitive tree-ring network, but also provides new insights into long-term regional moisture variations and offers a reference for future regional drought forecasts. In the future, more efforts are still needed to collect more old trees from CLP to extend the moisture reconstruction far back in time.

Acknowledgements. We greatly thank the editors and the anonymous reviewers for their helpful and constructive suggestions and comments on the manuscript. This work was jointly supported by the National Natural Science Foundation of China (41171170 and 40701196), National Basic Research Programme of China (2013CB955903) and the State Key Laboratory of Loess and Quaternary foundation (SKLLQG).

Edited by: J. Guiot

\section{References}

Braun, H., Christl, M., Rahmstorf, S., Ganopolski, A., Mangini, A., Kubatzki, C., Roth, K., and Kromer, B.: Possible solar origin of the 1,470-year glacial climate cycle demonstrated in a coupled model, Nature, 438, 208-211, 2005.

Briffa, K. R. and Jones, P. D.: Basic chronology statistics and assessment, in: Methods of Dendrochronology, edited by: Cook, E. R. and Kairiukstis, L. A., Kluwer Academic Publishers, Dordrecht, 137-152, 1990.

Büntgen, U., Tegel, W., Nicolussi, K., McCormick, M., Frank, D., Trouet, V., Kaplan, J. O., Herzig, F., Heussner, K.-U., Wanner, H., Luterbacher, J., and Esper, J.: 2500 years of European climate variability and human susceptibility, Science, 331, 578582, 2011.

Cai, Q. F. and Liu, Y.: Climatic response of Chinese pine and PDSI variability in the middle Taihang Mountains, north China since 1873, Trees, 27, 419-427, 2013.

Cai, Q. F., Liu, Y., Song, H. M., and Sun, J. Y.: Tree-ring-based reconstruction of the April to September mean temperature since 1826 AD for north-central Shaanxi Province, China, Sci. China Ser. D, 51, 1099-1106, 2008.

Cai, Q. F., Liu, Y., and Tian, H.: A dendroclimatic reconstruction of May-June mean temperature variation in north China since 1767 AD, Quatern. Int., 283, 3-10, 2013.

Chen, F., Yuan, Y. J., and Wei, W. S.: Climatic response of Picea crassifolia tree-ring parameters and precipitation reconstruction in the western Qilian Mountains, China, J. Arid Environ., 75, 1121-1128, 2011a.

Chen, F., Yuan, Y. J., Wei, W. S., Yu, S. L., and Zhang, T. W.: Correlations between the summer Asian Pacific oscillation index and the tree-ring width of Pinus massiniana from Sha county, Fujian province, Quatern. Sci., 31, 96-103, 2011b.

Chen, Z. J., He, X. Y., Cook, E. R., He, H. S., Chen, W., Sun, Y., and Cui, M. X.: Detecting dryness and wetness signals from treerings in Shenyang, Northeast China, Palaeogeogr. Palaeocl., 302, 301-310, 2011.

Chen, Z. J., Zhang, X. L., Cui, M. X., He, X. Y., Ding, W. H., and Peng, J. J.: Tree-ring based precipitation reconstruction for the forest-steppe ecotone in northern Inner Mongolia, China and its linkages to the Pacific Ocean variability, Global Planet. Change, 86-87, 45-56, 2012.

Cook, E. R.: A time-series analysis approach to tree-ring standardization, Dissertation for the Doctoral Degree, The University of Arizona, Tucson, 1985.

Cook, E. R. and Kairiukstis, L. A.: Methods of dendrochronology: applications in the environmental sciences, Kluwer Academic Publishers, Dordrecht, 394 pp., 1990.

Cook, E. R., Meko, D. M., Stahle, D. W., and Cleaveland, M. K.: Drought reconstructions for the continental United States, J. Climate, 12, 1145-1162, 1999.

Cook, E. R., Anchukaitis, K. J., Buckley, B. M., D’Arrigo, R. D., Jacoby, G. C., and Wright, W. E.: Asian monsoon failure and megadrought during the last millennium, Science, 328, 486-489, 2010.

Dai, A. G., Trenberth, K. E., and Qian, T.: A global dataset of Palmer drought severity index for 1870-2002: relationship with soil moisture and effects of surface warming, J. Hydrometeorol., 5, 1117-1130, 2004. 
Deng, Y., Gou, X. H., Gao, L. L., Zhao, Z. Q., Cao, Z. Y., and Yang, M. X.: Aridity changes in the eastern Qilian Mountains since AD 1856 reconstructed from tree-rings, Quatern. Int., 283, 7884, 2013.

Du, S., Norikazu, Y., Fukuju, Y., Kyoichi, O., Wang, S. Q., and Hou, Q. C.: The effect of climate on radial growth of Quercus Liaotungensis forest trees in Loess Plateau, China, Dendrochronologia, 25, 29-36, 2007.

Efron, B.: Bootstrap methods: another look at the jackknife, Ann. Stat., 7, 1-26, 1979.

Esper, J., Frank, D., Büntgen, U., Verstege, A., Luterbacher, J., and Xoplaki, E.: Long-term drought severity variations in Morocco, Geophys. Res. Lett., 34, L17702, doi:10.1029/2007GL030844, 2007.

Fang, K. Y., Gou, X. H., Chen, F. H., Yang, M. X., Li, J. B., He, M. S., Zhang, Y., Tian, Q. H., and Peng, J. F.: Drought variations in the eastern part of northwest China over the past two centuries: evidence from tree rings, Clim. Res., 38, 129-135, 2009.

Fang, K. Y., Gou, X. H., Chen, F. H., D’Arrigo, R., and Li, J .B.: Tree-ring based drought reconstruction for the Guiqing Mountain (China): linkages to the Indian and Pacific Oceans, Int. J. Climatol., 30, 1137-1145, 2010a.

Fang, K. Y., Davi, N., Gou, X. H., Chen, F. H., Cook, E., Li, J. B., and D'Arrigo, R.: Spatial drought reconstructions for central High Asia based on tree rings, Clim. Dynam., 35, 941-951, 2010b.

Fang, K. Y., Gou, X. H., Chen, F. H., Liu, C. Z., Davi, N., Li, J. B., Zhao, Z. Q., and Li, Y. J.: Tree-ring based reconstruction of drought variability (1615-2009) in the Kongtong Mountain area, northern China, Global Planet. Change, 80-81, 190-197, 2012.

Fang, K. Y., Frank, D., Gou, X. H., Liu, C. Z., Zhou, F. F., Li, J. B., and Li, Y. J.: Precipitation over the past four centuries in the Dieshan Mountains as inferred from tree rings: An introduction to an HHT-based method, Global Planet. Change, 107, 109-118, 2013.

Gao, P., Mu, X.-M., Li, R., and Wang, F.: Analyses of relationship between Loess Plateau erosion and sunspots based on wavelet transform, Hydrol. Earth Syst. Sci. Discuss., 8, 277-303, doi:10.5194/hessd-8-277-2011, 2011.

Gao, S. Y., Lu, R. J., Qiang, M. R., Hasi, E. D., Zhang, D. S., Chen, Y., and Xia, H.: Reconstruction of precipitation in the last 140 years from tree ring at south margin of the Tengger Desert, China, Chin. Sci. Bull., 50, 2487-2492, 2005.

Gou, X. H., Deng, Y., Chen, F. H., Yang, M. X., Fang, K. Y., Gao, L. L., Yang, T., and Zhang, F.: Tree ring based streamflow reconstruction for the Upper Yellow River over the past 1234 years, Chin. Sci. Bull., 55, 4179-4186, 2010.

Guan, W., Xiong, W., Wang, Y. H., Yu, P. T., He, C. Q., Du, A. P., and Liu, H. L.: Stem diameter growth of Larix principisrupprechtii and its response to meteorological factors in the north of Liupan Mountain, Scient. Silvae Sin., 43, 1-6, 2007.

Guo, Q. Y., Cai, J. N., Shao, X. M., and Sha, W. Y.: Studies on the Variations of East-Asian Summer Monsoon during AD 1873 2000, Chin. J. Atmos. Sci., 28, 206-215, 2004.

Hao, Z. X., Zheng, J. Y., Wu, G. F., Zhang, X. Z., and Ge, Q. S.: 1876-1878 severe drought in North China: Facts, impacts and climatic background, Chin. Sci. Bull., 55, 3001-3007, 2010.

Holmes, R. L.: Computer-assisted quality control in tree-ring dating and measurement, Tree-Ring Bull., 43, 69-75, 1983.
Kang, S. Y., Yang, B., Qin, C., Wang, J. L., Shi, F., and Liu, J. J.: Extreme drought events in the years 1877-1878, and 1928, in the southeast Qilian Mountains and the air-sea coupling system, Quatern. Int., 283, 85-92, 2013.

Koretsune, S., Fukuda, K., Chang, Z. Y., Shi, F. C., and Ishida, A. Effective rainfall seasons for interannual variation in $\delta^{13} \mathrm{C}$ and tree-ring width in early and late wood of Chinese pine and black locust on the Loess Plateau, China, J. Forest Res., 14, 88-94, 2009.

Liang, E. Y., Liu, X. H., Yuan, Y. J., Qin, N. S., Fang, X. Q., Huang, L., Zhu, H. F., Wang, L. L., and Shao, X. M.: The 1920s drought recorded by tree rings and historical documents in the semi-arid and arid areas of northern China, Climatic Change, 79, 403-432, 2006.

Liang, E. Y., Shao, X. M., Liu, H. Y., and Eckstein, D.: Tree-ring based PDSI reconstruction since AD 1842 in the Ortindag Sand Land, east Inner Mongolia, Chin. Sci. Bull., 52, 2715-2721, 2007.

Liang, E. Y., Eckstein, D., and Shao, X. M.: Seasonal cambial activity of relict Chinese pine at the northern limit of its natural distribution in North China - exploratory results, IAWA J., 30, 371-378, 2009.

Linderholm, H. W., Björklund, J. A., Seftigen, K., Gunnarson, B. E., Grudd, H., Jeong, J.-H., Drobyshev, I., and Liu, Y.: Dendroclimatology in Fennoscandia - from past accomplishments to future potential, Clim. Past, 6, 93-114, doi:10.5194/cp-6-93-2010, 2010 .

Linderholm, H. W., Liu, Y., Leavitt, S. W., and Liang, E. Y.: Dendrochronology in Asia, Quatern. Int., 283, 1-2, 2013.

Liu, Y., Cai, Q. F., Park, W.-K., An, Z. S., and Ma, L. M.: Tree-ring precipitation records from Baiyinaobao, Inner Mongolia since A.D. 1838, Chin. Sci. Bull., 48, 1140-1145, 2003 a.

Liu, Y., Park, W.-K., Cai, Q. F., Seo, J.-W., and Jung, H.-S.: Monsoonal precipitation variation in the East Asia since A.D. 1840: Tree-ring evidences from China and Korea, Sci. China Ser. D, 46, 1031-1039, 2003b.

Liu, Y., Cai, Q. F., Shi, J. F., Hughes, M. K., Kutzbach, J. E., Liu, Z. Y., Ni, F. B., and An, Z. S.: Seasonal precipitation in the southcentral Helan Mountain region, China, reconstructed from treering width for the past 224 years, Can. J. For. Res., 35, 24032412, 2005.

Liu, Y., Tian, H., Song, H. M., and Liang, J. M.: Tree-ring precipitation reconstruction in the Chifeng-Weichang region, China, and East Asian summer monsoon variation since A.D. 1777, J. Geophys. Res., 115, D06103, doi:10.1029/2009JD012330, 2010.

Liu, Y., Cai, Q. F., Song, H. M., An, Z. S., and Linderholm, H. W.: Amplitudes, rates, periodicities and causes of temperature variations in the past 2485 years and future trends over the centraleastern Tibetan Plateau, Chin. Sci. Bull., 56, 2986-2994, 2011.

Liu, Y., Sun, B., Song, H. M., Lei, Y., and Wang, C. Y.: Tree-ringbased precipitation reconstruction for Mt. Xinglong, China, since AD 1679, Quatern. Int., 283, 46-54, 2013.

Ma, J. J., Gao, X. Q., and Qu, Y. L.: The character of precipitation and its relation to climate change over north China in spring and summer, Clim. Environ. Res., 11, 321-329, 2006.

Ma, Z. G. and Fu, C. B.: Some evidences of drying trend over northern China from 1951 to 2004, Chin. Sci. Bull., 51, 2913-2925, 2006. 
Mann, M. E. and Lees, J. M.: Robust estimation of background noise and signal detection in climatic time series, Climatic Change, 33, 409-445, 1996.

Meko, D. M. and Graybill, D. A.: Tree-ring reconstruction of Upper Gila River discharge, Water Resour. Bull., 31, 605-616, 1995.

Ohyama, M., Yonenobu, H., Choi, J.-N., Park, W.-K., Hanzawa, M., and Suzuki, M.: Reconstruction of northeast Asia spring temperature 1784-1990, Clim. Past, 9, 261-266, doi:10.5194/cp-9-2612013, 2013.

Pederson, N., Jacoby, G. C., D’Arrigo, R. D., Cook, E. R., Buckley, B. M., Dugarjav, C., and Mijiddorj, R.: Hydrometeorological reconstructions for northeastern Mongolia derived from tree rings: AD 1651-1995, J. Climate, 14, 872-881, 2001.

Qian, W. H., Lin, X., and Zhu, Y. F.: Global and China temperature changes associated with the inter-decadal variations of East Asian summer monsoon advances, Chin. Sci. Bull., 30, 39233930, 2012.

Raspopov, O. M., Dergachevb, V. A., and Kolström, T.: Periodicity of climate conditions and solar variability derived from dendrochronological and other palaeo-climatic data in high latitudes, Palaeogeogr. Palaeocl., 209, 127-139, 2004.

Sonett, C. P., Finney, S. A., and Berger, A.: The spectrum of radiocarbon, Philos. T. Roy. Soc. Lond. A, 330, 413-426, 1990.

Song, H. M. and Liu, Y.: PDSI variations at Kongtong Mountain, China, inferred from a 283-year Pinus tabulaeformis ring width chronology, J. Geophys. Res., 116, D22111, doi:10.1029/2011JD016220, 2011.

Stokes, M. A. and Smiley, T. L.: An Introduction to Tree-Ring Dating, The University of Arizona Press, Tucson, 1968.

Sun, J. Y., Liu, Y., Sun, B., and Wang, R. Y.: Tree-ring based PDSI reconstruction since $1853 \mathrm{D}$ in the source of the Fenhe River Basin, Shanxi Province, China, Sci. China Ser. D, 55, $1847-$ 1854, 2012.

Sun, J. Y., Liu, Y., Wang, Y. C., Bao, G., and Sun, B.: Treering based runoff reconstruction of the upper Fenhe River basin, North China, since 1799 AD, Quatern. Int., 283, 117-124, 2013.

Tei, S., Sugimoto, A., Yonenobu, H., Hoshino, Y., and Maximov, T. C.: Reconstruction of summer Palmer Drought Severity Index from $\delta^{13} \mathrm{C}$ of larch tree rings in East Siberia, Quatern. Int., 290291, 275-281, 2013.

Tian, Q. H., Gou, X. H., Zhang, Y., Peng, J. F., Wang, J. S., and Chen, T.: Tree-ring based drought reconstruction (A.D. 18552001) for the Qilian Mountains, Northwestern China, Tree-Ring Res., 63, 27-36, 2007.

Wang, Y.: The preliminary study on the natural disaster in north Shaanxi during 1923-1931, Meteorol. Disast. Reduc. Res., 29, 34-38, 2006.

Wei, F. Y.: Statistical diagnosis and prediction technique applied in modern climatology, China Meteorological Press, Beijing, 4344, 2007.

Wei, J., Zhang, Q. Y., and Tao, S. Y.: Physical causes of the 1999 and 2000 summer sever drought in north China, Chin, J. Atmos. Sci., 28, 125-137, 2004.

Wigley, T. M. L., Briffa, K. R., and Jones, P. D.: On the average value of correlated time series, with applications in dendroclimatology and hydrometeorology, J. Clim. Appl. Meteorol., 23, 201-213, 1984.
Xiao, G. J., Zhang, Q., and Xiong, Y. C.: Integrating rainwater harvesting with supplemental irrigation into rain-fed spring wheat farming, Soil Till. Res., 93, 429-437, 2007.

Xiao, L. B., Ye, Y., and Wei, B. Y.: Revolts frequency during 16441911 in north China plain and its relationship with climate, Adv. Clim. Change Res., 2, 218-224, 2011.

Xu, H. C.: Pinus tabulaeformis, Science press, Beijing, 1990.

$\mathrm{Xu}$, J. H.: Sun, climate, famine and folk nation transfer, Sci. China Ser. D, 28, 366-384, 1998.

Yang, B., Bräuning, A., Liu, J. J., Davis, M. E., and Shao, Y. J.: Temperature changes on the Tibetan Plateau during the past 600 years inferred from ice cores and tree rings, Global Planet. Change, 69, 71-78, 2009.

Yao, Y. B., Wang, Y. R., Li, Y. H., and Zhang, X. Y.: Climate warming and drying and its environmental effects in the Loess Plateau, Resour. Sci., 27, 146-152, 2005.

Yi, L., Yu, H. J., Ge, J. Y., Lai, Z. P., Xi, X. Y., Qom, L., and Peng, S. Z.: Reconstructions of annual summer precipitation and temperature in north-central China since $1470 \mathrm{AD}$ based on drought/flood index and tree-ring records, Climatic Change, 110, 469-498, 2012.

Yuan, L.: History of the Northwest China Famine, Gansu People's Publishing House, Lanzhou, p. 6321, 1994.

Zeng, G., Ni, D. H., Li, Z. X., and Li, C. H.: Advances in the research of inter-decadal variation of East Asian summer Monsoon, Meteor. Disast. Reduc. Res., 32, 1-7, 2009.

Zeng, Z. Z., Fang, X. Q., Ye, Y., and Zhang, X. Z.: Comparison of disaster situation and causes of three extreme droughts in China over the Past 300 Years, J. Catastro., 24, 116-122, 2009.

Zhang, D. D., Lee, H., Wang, C., Li, B., Pei, Q., Zhang, J., and An, Y.: The causality analysis of climate change and large-scale human crisis, P. Natl. Acad. Sci. USA, 108, 17296-17301, 2011.

Zhang, D. E.: Variation of dry-wet climate and severe drought events as revealed in the climate records of China over the past 1000 years, Sci. Technol. Rev., 8, 47-49, 2004.

Zhang, Q. B., Chen, G. D., Yao, T. D., Kang, X. C., and Huang, J. G.: A 2,326-year tree-ring record of climate variability on the northeastern Qinghai-Tibetan Plateau, Geophys. Res. Lett., 30, 1739, doi:10.1029/2003GL017425, 2003.

Zhang, Y. B., Zheng, H. M., Long, R. Z., and Yang, B. C.: Seasonal cambial activity and formation of phloem and xylem in eight forest tree species grown in North China, Sci. Silvae Sin., 18, 365-379, 1982.

Zhang, Z. B., Tian, H. D., Cazelles, B., Kausrud, K. L., Bräuning, A., Guo, F., and Stenseth, N. C.: Periodic climate cooling enhanced natural disasters and wars in China during AD 10-1900, P. Roy. Soc. B, 277, 3745-3753, 2010.

Zhao, P., Zhu, Y. N., and Zhang, R. H.: An Asian-Pacific teleconnection in summer tropospheric temperature and associated Asian climate variability, Clim. Dynam., 29, 293-303, 2007.

Zhao, P., Chen, J. M., Xiao, D., Nan, S. L., Zou, Y., and Zhou, B. T.: Summer Asian-Pacific oscillation and its relationship with atmospheric circulation and monsoon rainfall, Acta Meteorol. Sin., 22, 455-471, 2008.

Zhou, Q. G., Qu, X. W., and Cheng, Y.: The natural disasters in Northern China during late Qing Dynasty, J. Soc. Sci. Hunan Norm. Univ., 2, 122-126, 2010. 
Zhou, X. J., Zhao, P., and Liu, G.: Asian-Pacific Oscillation index and variation of East Asian summer monsoon over the past millennium, Chin. Sci. Bull., 54, 3768-3771, 2009.
Zhu, H. F., Fang, X. Q., Shao, X. M., and Yin, Z. Y.: Tree ringbased February-April temperature reconstruction for Changbai Mountain in Northeast China and its implication for East Asian winter monsoon, Clim. Past, 5, 661-666, doi:10.5194/cp-5-6612009, 2009. 